\title{
Incisivo central permanente avulsionado. Conducta y caso clínico
}

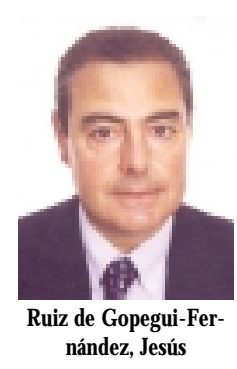

\section{Avulsed permanent central incisor. Attitude and clinical report}

\section{Ruiz de Gopeguil - Fernández, Jesús}

Práctica limitada a Endodoncia

\section{Correspondencia}

Jesús Ruiz de Gopegui Fernández Po Sagasta 9, (pasaje) bajo 50008 Zaragoza
Resumen. La avulsión dental traumática es una urgencia odontológica. Para conseguir la reinserción y fijación del diente en su alvéolo se requiere que la vitalidad del ligamento periodontal sea conservada. En estos casos el factor tiempo, la cuidadosa manipulación y preservación del diente avulsionado en el medio adecuado son claves para el éxito del tratamiento.

Palabras clave. Diente avulsionado, Reimplante.

Abstract. Traumatic dental avulsion is a dental emergency. Reinsertion and fixation of the tooth requires an appropriate preservation of the vitality of the periodontal tissues. In these cases, the success of this procedure depends on time, carefull handling and storage of the avulsed tooth in an appropiate media.

Key words. Avulsed tooth, Replantation.

\begin{tabular}{ccc}
\hline Fecha recepción & Fecha última revisión & Fecha aceptación \\
$07-04-2003$ & $30-06-2003$ & $01-08-2003$ \\
\hline
\end{tabular}

BIBUD [1138-123X (2003)8:4; julio-agosto 349-468]

Ruiz de Gopegui-Fernández J. Incisivo central permanente avulsionado. Conducta y caso clínico. RCOE 2003;8(4):429-437. 


\section{Introducción}

Una de las situaciones más dramáticas y urgentes que se nos puede presentar en la práctica diaria de nuestra profesión es la avulsión traumática de un diente, ya que de la precisión y rapidez con que se actúe, dependerá su mantenimiento a largo plazo en boca. Son de suma importancia el espacio de tiempo que permanece ese diente fuera de su alvéolo antes de su reimplante, su mantenimiento en medio húmedo y el enorme impacto psicológico que provoca en el paciente y en el entorno familiar. Este trabajo pretende mostrar - paso a paso- mediante una amplia iconografía, la solución dada a un caso de avulsión dental y refrescar las pautas de actuación que permitan manejar con éxito estas situaciones clínicas.

Cuando nos comunican telefónicamente que un niño ha perdido un diente por una caída en el «recreo» del colegio y que lo envían a la consulta, lo primero que tenemos que indagar es si ha sido hallado ese diente, si tiene su raíz íntegra y si en ésta se encuentra adherida sangre coagulada con suciedad (polvo, tierra, etc,) porque de ser así, tiene que ser lavada bajo un chorro de agua corriente, $y$ no sumergirla en alcohol $u$ otros productos no fisiológicos, sujetando el diente por la corona y, sin que la raíz sea manipulada, cepillada o frotada por medio alguno. Sólo así se preservan íntegras las fibras y células del ligamento periodontal ${ }^{1 * *}$, tan necesarias para el éxito del tratamiento. Sin pérdida de tiempo, el diente tiene que ser reubicado en su alvéolo sin más presión que la ejercida con los dedos antes de ser enviado a la consulta ${ }^{2 * *}$.

Si no es posible la reposición alveolar por las causas que fueren, tales como la fractura del hueso, heridas en partes blandas, hemorragia o las dudas lógicas que puedan asaltar a la persona que presta el auxilio (temor, indecisión, ausencia de visibilidad), el diente debe ser mantenido en un medio húmedo -nunca en seco-. Preferimos en la leche entera fría que está al alcance de todos y en todas partes.

La solución balanceada de Hanks se considera un medio ideal de transporte ya que entre sus propiedades está la de mantener la vitalidad de las fibras y células periodontales durante varias horas ${ }^{3,4}$. Si no es posible, se puede trasladar en suero fisiológico, porque la propia saliva del niño no se considera el medio adecuado de mantenimiento debido a su flora bacteriana y debe ser trasladado a la consulta con toda rapidez para su reinserción alveolar. Un tiempo extraoral del diente inferior a 60 minutos puede conseguir un índice de éxito superior al 90\% de los casos mientras que un tiempo extraoral superior a 120 minutos $^{5}$ disminuye las posibilidades de éxito hasta en un $90 \%$ de los casos. Se deduce que la celeridad y exactitud en la ejecución de las maniobras a desarrollar para minimizar el riesgo de pérdida del diente ${ }^{6,7 *}$ son vitales.

Si el niño nos llega con el diente bien insertado en el alvéolo -comprobación que incluirá aparte de la inspección visual y radiográfica el chequeo de la mordida- lo ferulizaremos pasivamente a los dientes adyacentes con alambre flexible y composite, maniobra que puede resultar harto complicada en traumatismos severos por la dificultad al aislar el campo, grabar con ácido y aplicar el adhesivo y fraguado del composite. La férula será mantenida de 7 a 10 días. Rechazamos las férulas-ligaduras circunferenciales de alambre por favorecer la contaminación bacteriana y las férulas rígidas por favorecer el riesgo de reabsorción externa $a^{2 * 8,8 *}$. Acto seguido inspeccionaremos y trataremos adecuadamente las heridas de las partes blandas si las hubiere sin olvidarnos del examen radiográfico de los labios y tejidos blandos heridos, ya que es posible que haya fragmentos coronales y/o cuerpos extraños en su interior.

En el caso de que el paciente acuda a la consulta con el diente fuera del lecho dentario, lo mantendremos en medio húmedo en todo momento, irrigaremos el alvéolo con suero salino y aspiraremos -sin introducirnos en élsuavemente el coágulo, sin curetearlo ni impulsar en su interior el chorro de aire; a continuación lavaremos el diente con suero fisiológico sin eliminar con cepillado los coágulos o restos que pudieran permanecer adheridos a la raíz (si los hay se pueden retirar cuidadosamente con una esponja húmeda) e insertaremos el diente en su alvéolo. Si éste se ha fracturado reduciremos la fractura o, en el caso de que no podamos alojar el diente en su interior introduciremos un instrumento romo capaz de remodelar hueso dentro del lecho alveolar y si se han distendido ambas corticales tras el reimplante, los comprimiremos con los dedos. Como se ha indicado anteriormente, ferulizaremos y suturaremos las dislaceraciones de los tejidos blandos, especialmente en la región cervical. 
En todos los casos de avulsión dentaria, prescribiremos la cobertura antibiótica-analgésica necesaria, la profilaxis antitetánica si se precisa e insistiremos en la importancia de mantener la máxima higiene oral (limpiar y retirar cuidadosamente los restos alimentarios, lavados con colutorios de clorhexidina) además de recomendar una dieta blanda y evitar morder con los dientes afectados y con los feruliza$\operatorname{dos}^{10^{*}}$. La férula será eliminada tan pronto como se compruebe la estabilidad del diente en su alvéolo, pero en el caso de fracturas óseas que produzcan movilidad, el mantenimiento de la férula requerirá un período de tiempo más prolongado (hasta 8 semanas) $)^{2 *, 8,811^{* *}}$

El tratamiento endodóntico de los dientes avulsionados va a depender por un lado del grado de desarrollo radicular y por otro del tiempo que ha permanecido fuera de su alvéo$10^{8,11^{* *, 12}}$. Si el ápice es divergente y el tiempo extraoral es inferior a dos horas, reimplantaremos en un intento de revitalizar la pulpa, revisaremos al paciente cada tres o cuatro semanas para detectar posible patología, que si se presenta, nos obligará a eliminar la pulpa cameral y radicular, a limpiar completamente el conducto y a rellenarlo con hidróxido cálcico. Gracias a él, nos beneficiaremos de su potencial osteogénico, $\mathrm{pH}$ alcalino $(12,6)$ y acción bactericida Cvek $1972^{13}$.

Si el ápice está abierto y el tiempo extraoral es superior a dos horas, extirparemos el tejido pulpar, haremos limpieza exhaustiva del conducto y lo rellenaremos con hidróxido de calcio. Revisaremos al paciente cada seis a ocho semanas para valo-

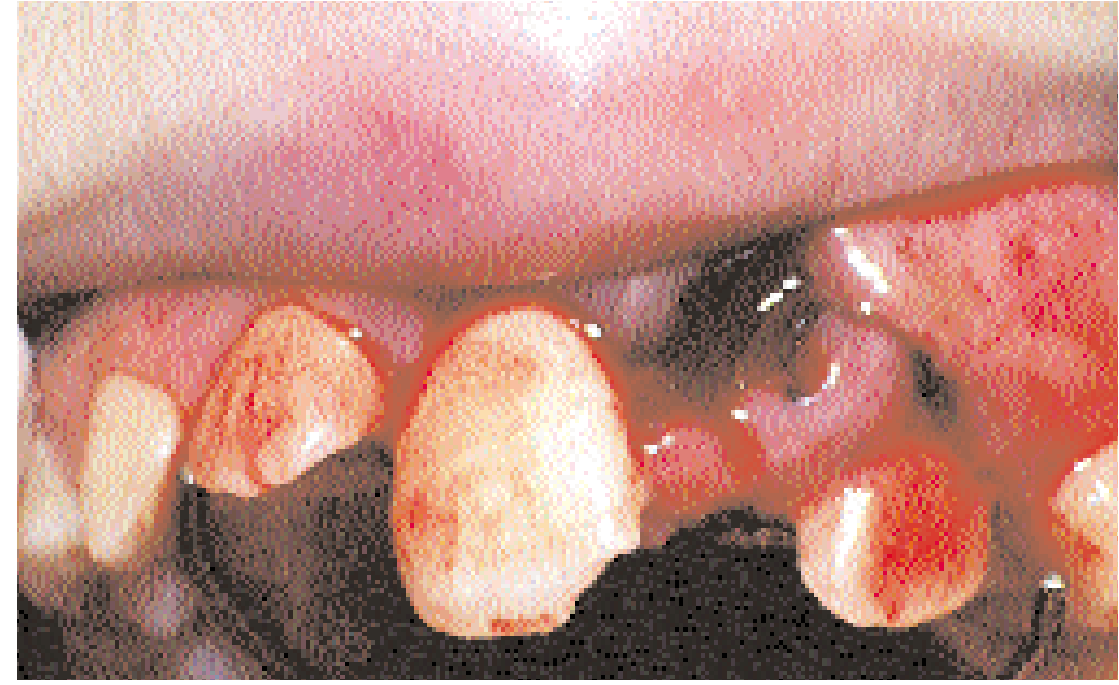

Figura 1. Aspecto tras la avulsión a los 30-45 minutos del accidente.

rar la evolución y sustituir el hidróxido de calcio si se ha reabsorbi$\mathrm{do}^{8,11^{* *}, 14,15}$.

Cuando el diente tiene el ápice parcial o totalmente cerrado y el tiempo extraoral es inferior a dos horas, entre siete y diez días después de la avulsión eliminaremos la pulpa cameral y la del conducto radicular y lo rellenaremos con hidróxido de calcio puro, manteniéndolo entre diez días y seis a doce meses ${ }^{14,16}$ para prevenir la resorción inflamatoria radicular. La obturación tridimensional con gutapercha y cemento sellador del conducto radicular se realiza después de retirar el hidróxido de calcio.

Si el diente tiene el ápice cerrado y un tiempo extraoral superior a dos horas $^{17}$, se puede realizar la endodoncia tanto intra como extraoralmente, poniendo especial atención en no dañar manual o químicamente la superficie radicular.

No olvidemos en las dos primeras semanas descartar la presencia de otras posibles fracturas radiculares no detectadas en el momento del traumatismo, para poder realizar la terapia adecuada que requiera la situación clínica y, en las revisiones periódicas, la exploración de los dientes adyacentes y de los antagonistas, comprobando su vitalidad pulpar, desarrollo radicular, cambios en la luz de los conductos radiculares, etc.

Por último, informaremos al paciente y a sus padres el riesgo que implican estos procesos, las posibilidades de éxito o fracaso, las complicaciones en su evolución, la posible afectación en el transcurso del tiempo de otros dientes implicados en el traumatismo, la importancia de seguir escrupulosamente las indicaciones, la necesidad de informar al dentista de cualquier cambio o síntoma que se presente para poder tener un control de la evolución del paciente durante los años siguientes y de las complicaciones potenciales -reabsorciones inflamatorias debidas a reemplazamiento o anquilosis- que podrán provocar en el futuro la pérdida del diente. 


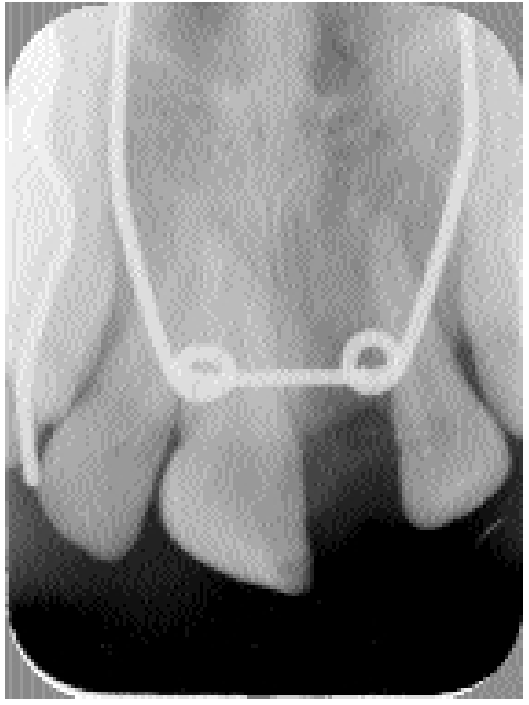

Figura 2. Radiografía que muestra la ausencia del incisivo.

\section{Caso clínico}

Niña de once años de edad en tratamiento ortodóncico por maloclusión importante, tiene una caída en el patio de recreo del colegio y sufre la avulsión del incisivo central superior izquierdo que tras ser recogido del suelo, es introducido en un vaso con suero fisiológico y enviado a su dentista, el cual nos la refiere previa llamada telefónica a nuestra consulta. Por teléfono se pregunta por el tiempo extraoral (inferior a 30 minutos), el estado de la raíz (su integridad) y por el desarrollo radicular (ápice cerrado), por la posibilidad de reimplantar in situ (prefieren referirla dada la proximidad entre ambas consultas) $y$, por el estado general de la niña (asustada pero sin alteración de la consciencia o traumatismo facial severo). El diente avulsionado es transportado como venía desde el colegio: dentro de un vaso con suero fisiológico.

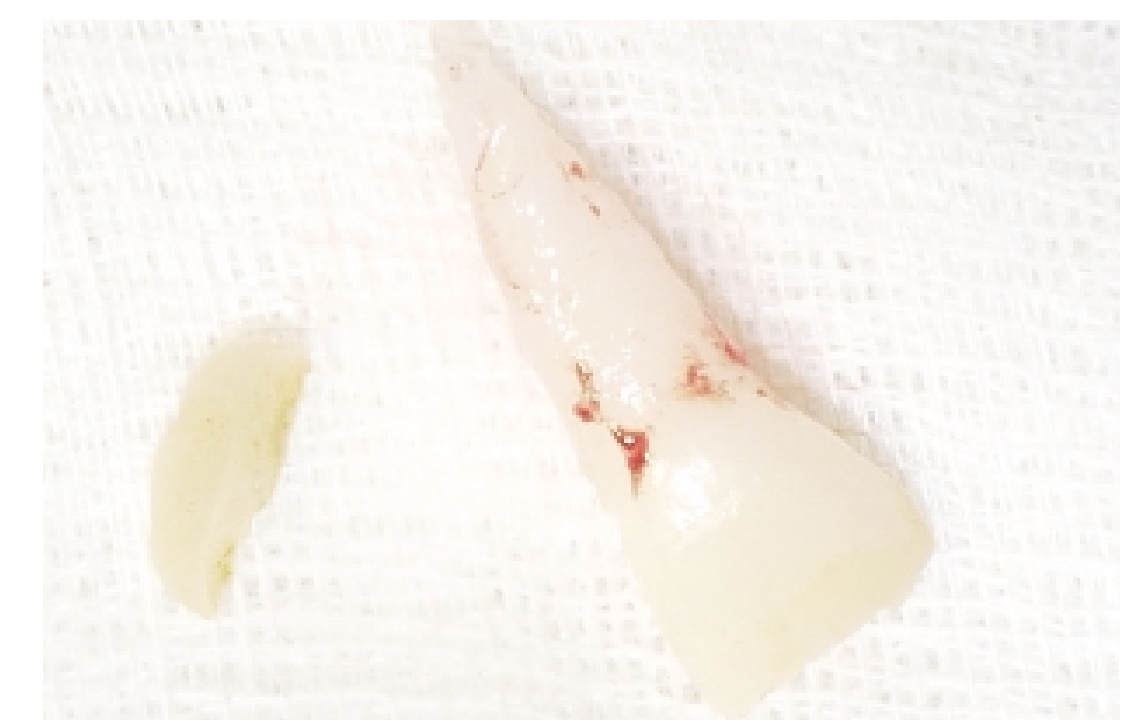

Figura 3. Estado en el que nos llegan el diente y la restauración desde el colegio.

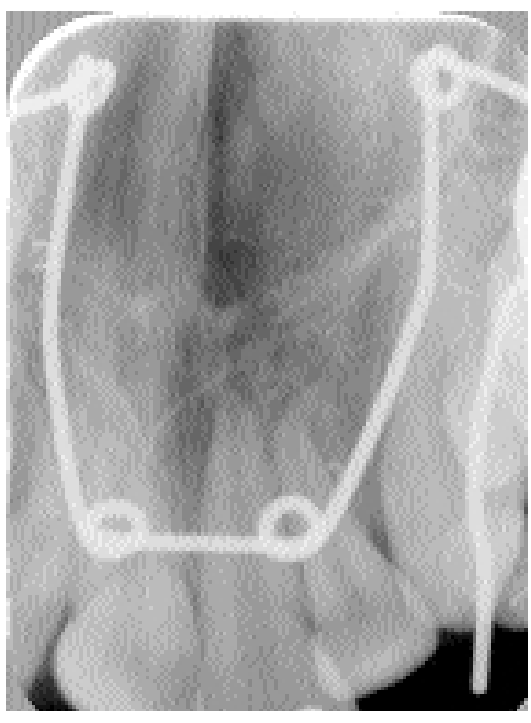

Figura 4. Radiografía del diente reimplantado en su alvéolo.

Aproximadamente 45 minutos después del accidente está sentada en el sillón dental con la historia clínica completada (antecedentes, alergias, vacunaciones en vigor, etc.), se han limpiado con suero y gasa los labios y

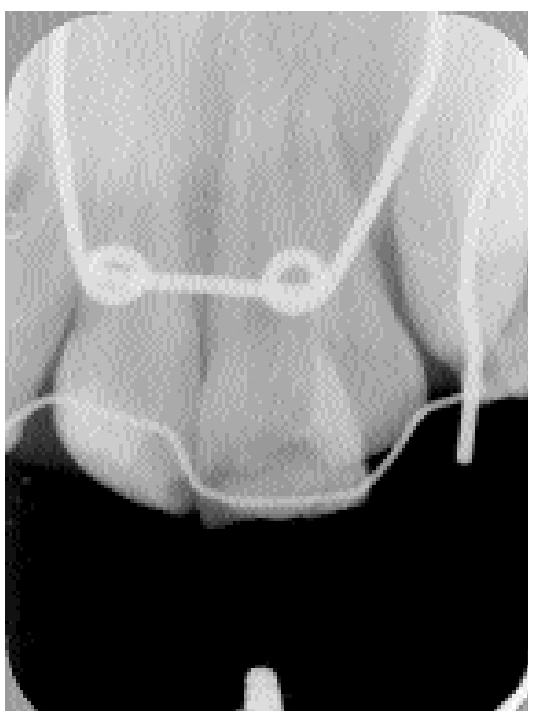

Figura 5. Radiografia que muestra la disposición de la férula adherida al diente avulsionado y a los dientes contiguos, adaptada a su malposición.

partes blandas, se ha aplicado vaselina en los labios y en las comisuras para facilitar su manejo (fig. 1), se ha tomado una radiografía intraoral (fig. 2), se ha inspeccionado el alvéolo dentario que no presenta signos de contusión, 


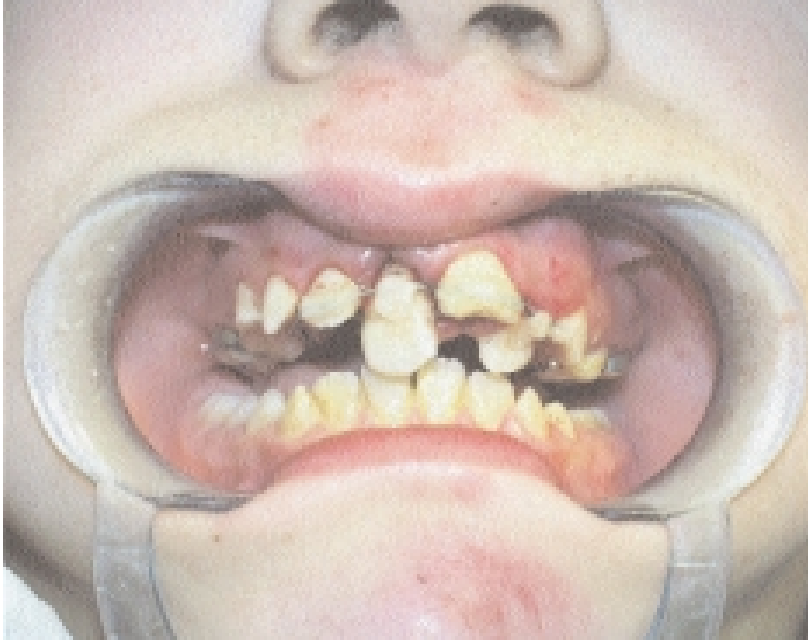

Figura 6. Aspecto de la ferulización que se extiende desde el 1.2 hasta el 2.3.

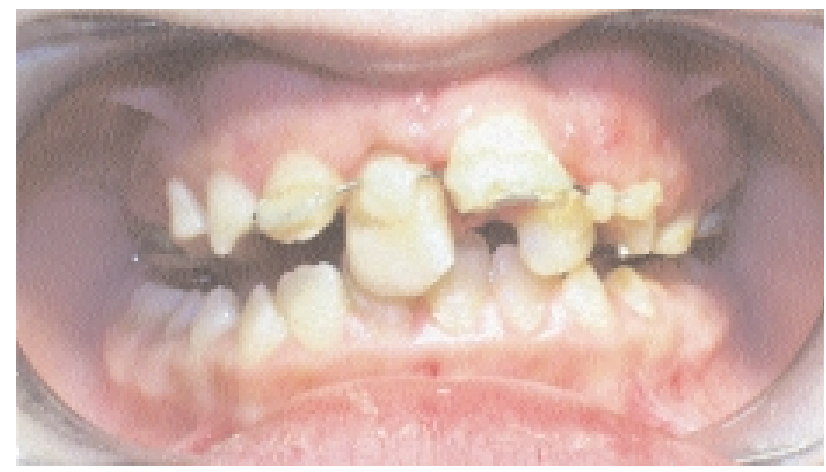

Figura 7. Higiene de la boca a los siete días.

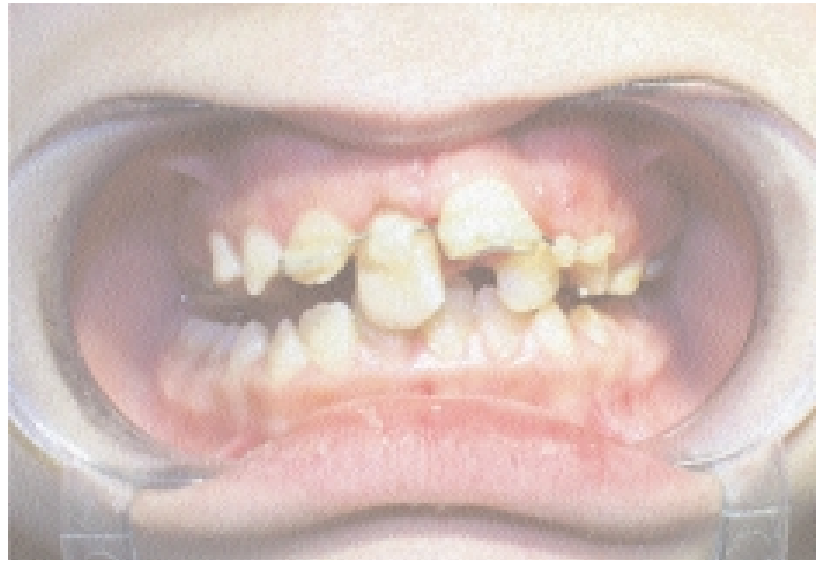

Figura 8. Control de la higiene oral.

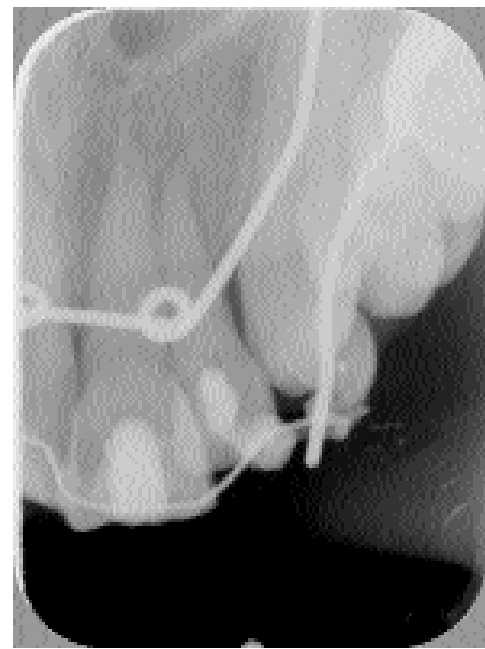

Figura 9. Retirada de la férula tras la introducción de hidróxido cálcico en 2.1 y 2.2 . se ha retirado suavemente el coágulo mediante lavado con suero fisiológico, se ha comprobado la integridad del hueso alveolar y del diente avulsionado (que afortunadamente está bastante limpio de polvo y suciedad y mantenido húmedo en suero hasta el momento del reimplante) (fig. 3). La niña es anestesiada con Octocaine ${ }^{\circledR}$ 1:100000. Acto seguido se explica a los padres (y a la niña) el tratamiento que se va a realizar haciendo especial mención en la importancia de seguir las instrucciones que se les van a dar, las posibles complicaciones que se puedan presentar a corto y medio plazo tanto en ese como en otros dientes (que se valorarán en sucesivas visitas) y, se solicita su consentimiento al tiempo que se explica pormenorizadamente el plan de tratamiento a desarrollar.

Se inicia tomando el diente por la corona, lo introducimos suavemente en su alojamiento, en el alvéolo, comprobando que está correctamente ubicado (fig. 4) manteniéndolo en su posición con nuestro dedo índice contra el borde incisal presionando en dirección apical. Se realiza grabado ácido del esmalte de todo el grupo anterior, lavado, secado y aplicación de «bonding» más alambre flexible previamente calentado al rojo vivo para que pierda su memoria molecular- y se fija a los dientes contiguos con un composite de fraguado fotopolimerizable (figs. 5 y 6 ).

Una vez conseguida la estabilidad del diente en su alojamiento, se termina la ferulización con el composite -maniobra complicada por la maloclusión de la niña- se pule con los discos apropiados para evitar aristas y/o bordes cortantes que pudieran erosionar los labios o la lengua además de la retención de placa bacteriana y, con la urgencia ya resuelta en un pla- 

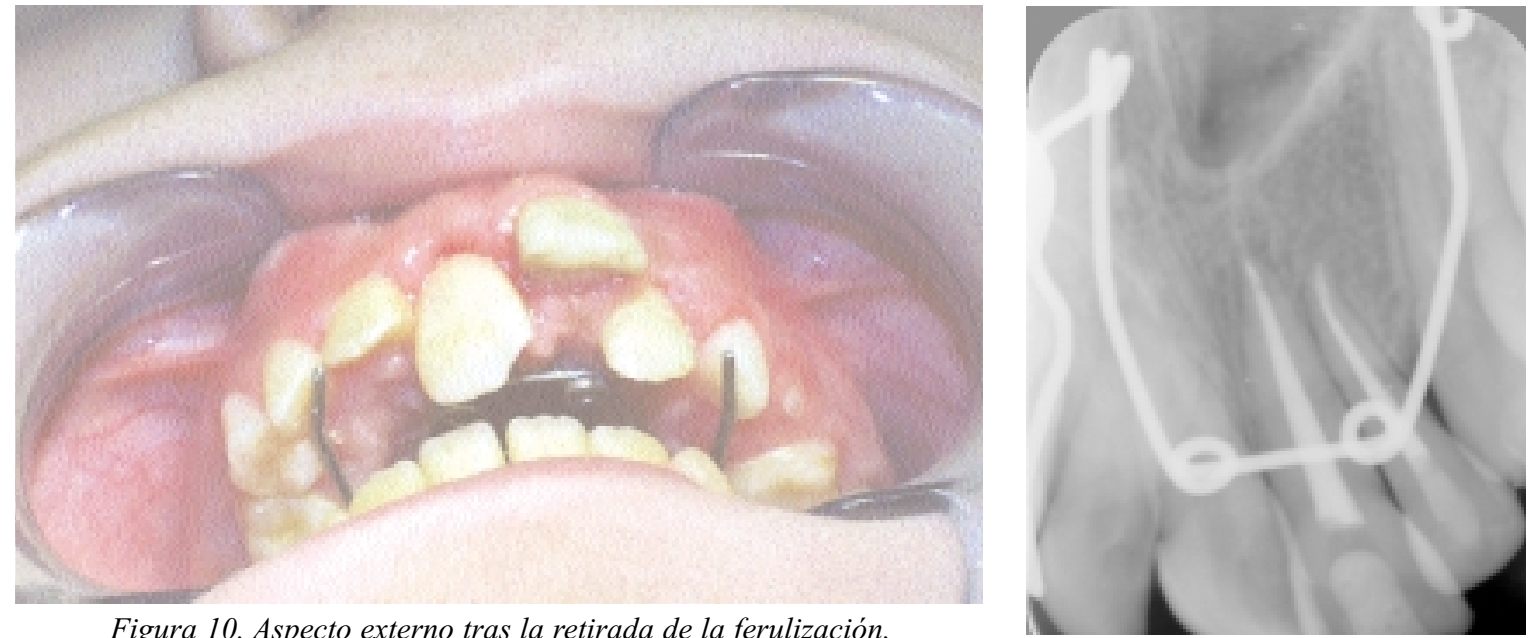

Figura 11.

Obtura-

ción con

gutaper-

cha de 2.1

y 2.2 a las

tres sema-

nas del

traumatis-

Figura 10. Aspecto externo tras la retirada de la ferulización.

mo.

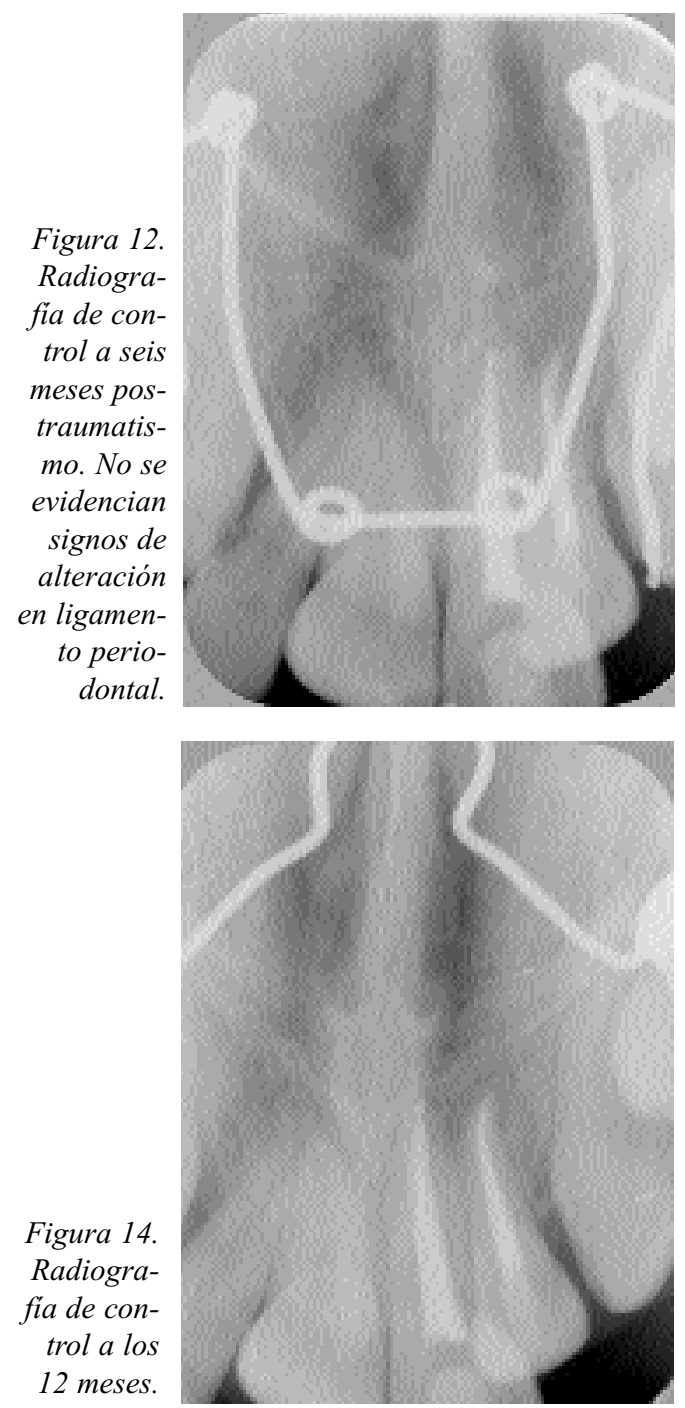

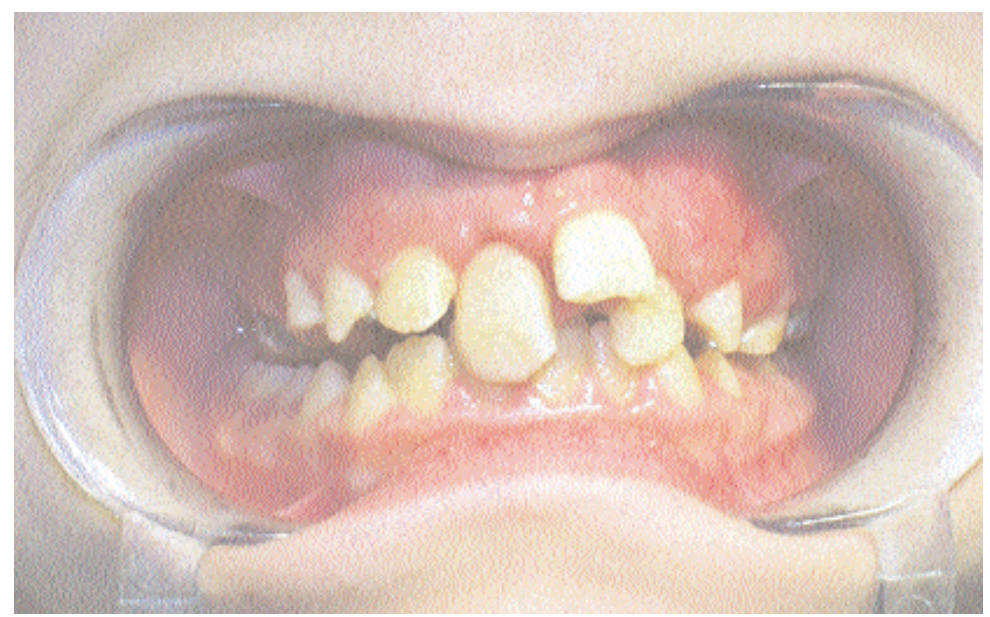

Figura 13. Aspecto de los tejidos blandos y control de la higiene a los seis meses del traumatismo.

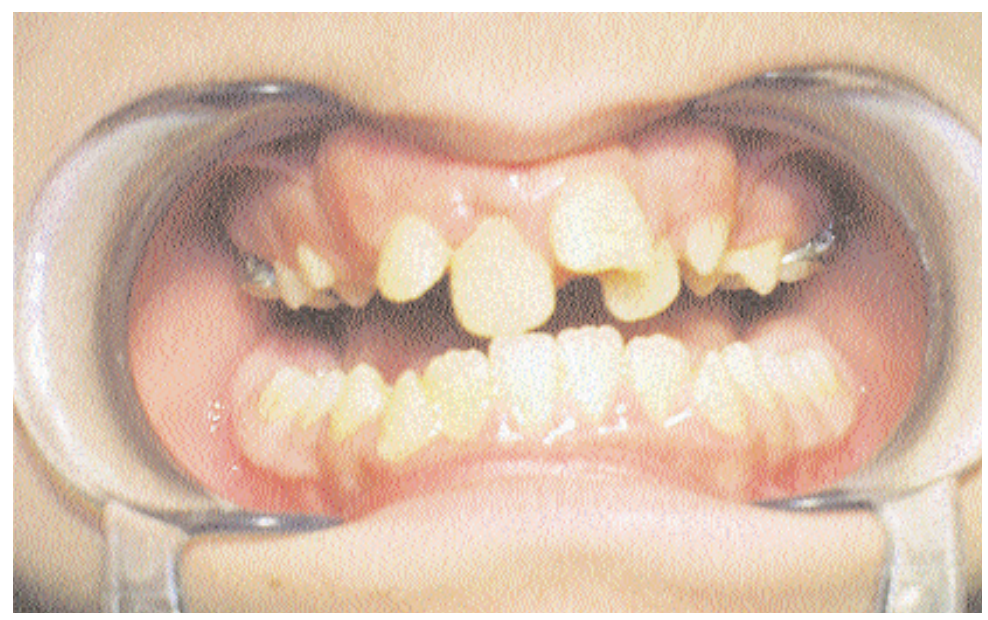

Figura 15. Aspecto externo a los 12 meses.

RCOE, 2003, Vol 8, №4, 429-437 


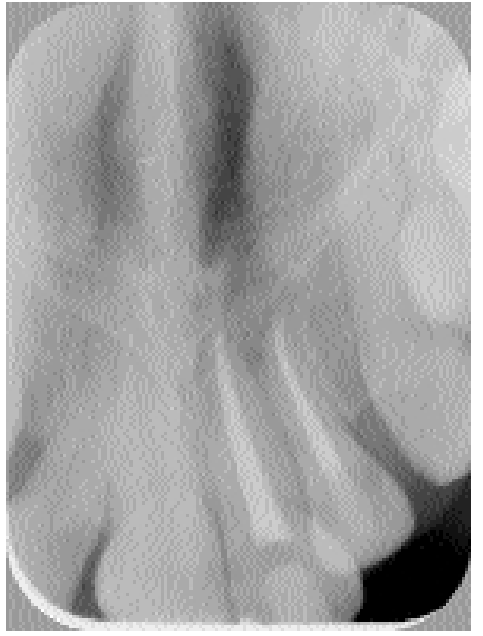

Figura 16. Radiografia de control a los 18 meses.

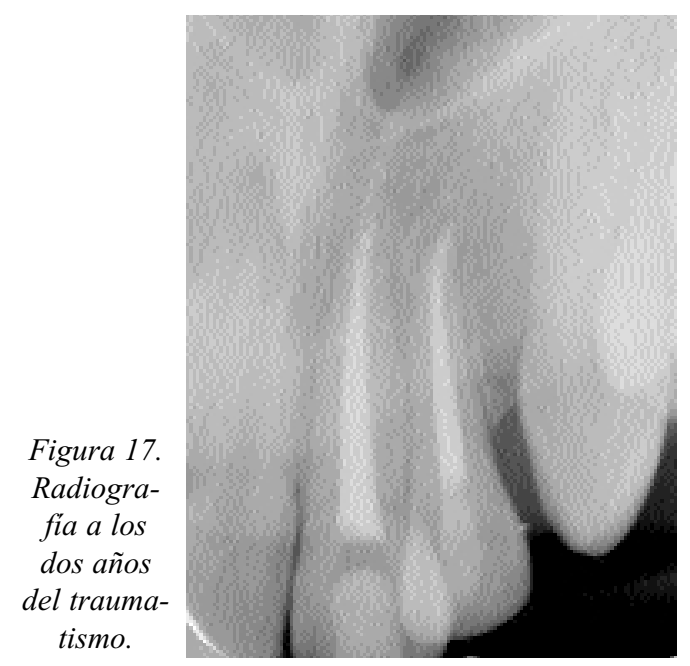

Figura 17 Radiografía a los dos años del traumatismo.

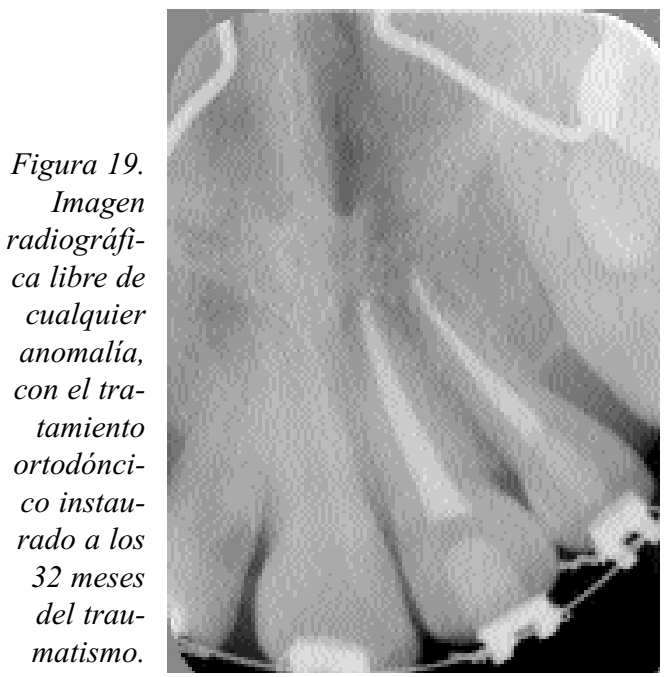

zo de tiempo inferior a 60-70 minutos desde el momento de la avulsión (fue fundamental para la rapidez de la ejecución de las maniobras el altísimo grado de cooperación por parte de la niña y de sus padres), explicamos los pasos que se darán en los días sucesivos. Se instruye a los padres para que puedan realizar una buena higiene oral de la niña (cepillado, colutorios, frecuencia, etc.) así como de la dieta blanda a seguir. Prescribimos la toma de amoxicilina 500mg/8h - 7 días e ibuprofeno como analgésico antiinflamatorio. Co- mo la madre confirma que la paciente ha sido revacunada contra el tétanos, prescindimos de ella.

Cinco días después realizamos: pruebas de vitalidad pulpar térmicas y eléctricas que resultaron negativas en 2.1 y 2.2 , control radiográfico de la situación del diente reimplantado, control que aprovechamos para comprobar la ausencia de fracturas radiculares en los dientes adyacentes. Eliminamos con un pulido suave los restos de placa bacteriana en las zonas que no había sido eliminada (figs. 7 y 8) y a las dos semanas del accidente

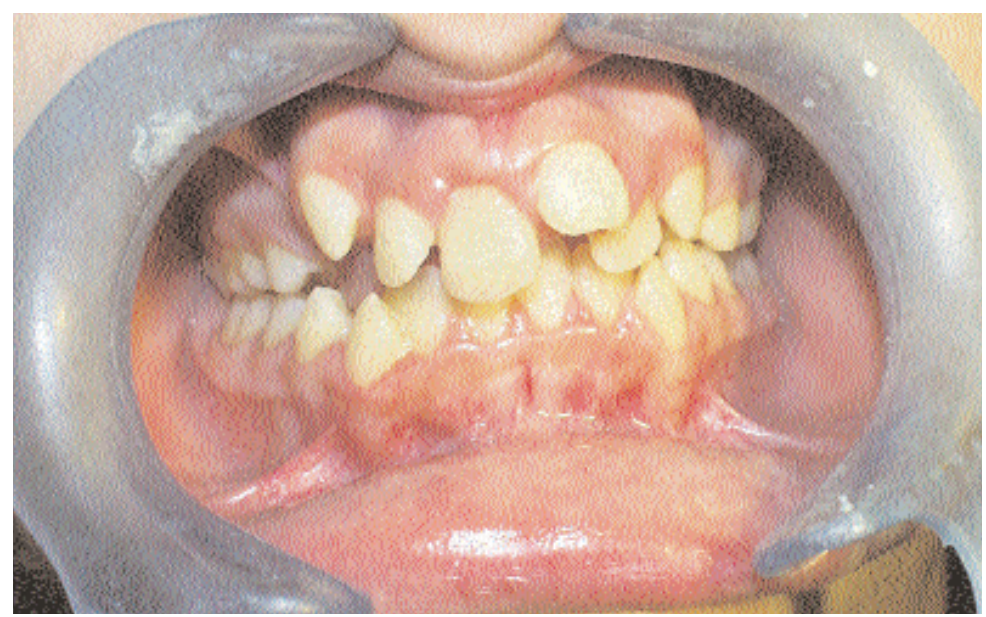

Figura 18. Aspecto externo a los dos años.

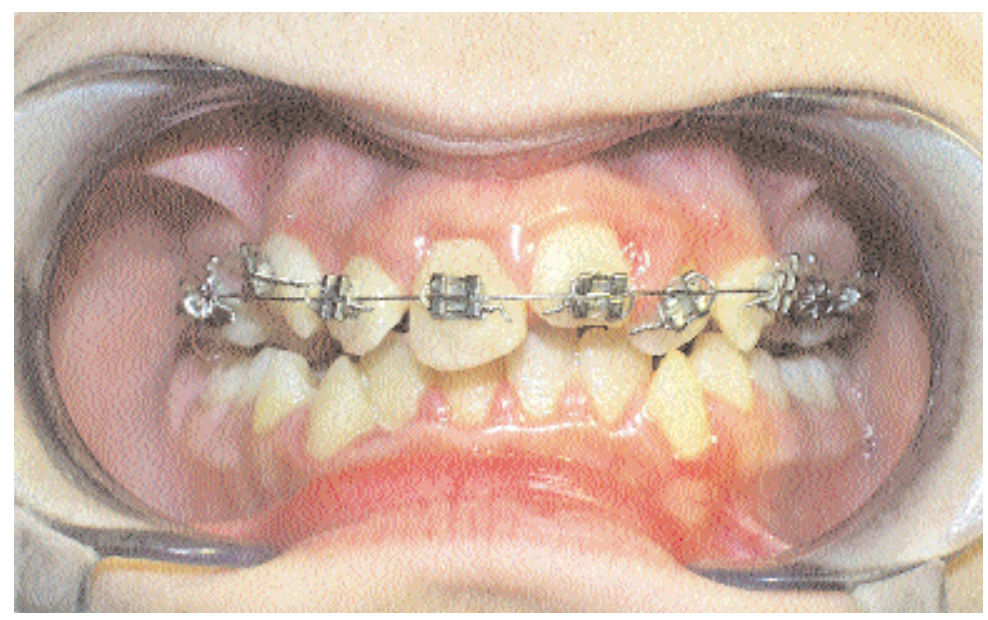

Figura 20. Aspecto en fase de corrección ortodóncica. 
efectuamos la apertura cameral en ambos incisivos maxilares izquierdos con relleno hasta el ápice de hidróxido cálcico (fig. 9), retirando la férula de alambre y composite tras comprobar la estabilidad de ambos dientes (fig. 10). Ocho días después se hicieron las endodoncias de los dientes afectados 2.1 y 2.2 (fig. 11) y se la emplazó para una nueva revisión tres meses después insistiendo en la importancia de mantener una buena higiene constatándose una favorable evolución.

Los controles subsiguientes a los seis meses radiográfico y de higiene (figs. 12 y 13), doce meses (figs. 14 y 15) y dieciocho meses (fig. 16) mostraron una buena evolución de todo el proceso, sin que en las radiografías se apreciaran signos de reabsorción o alteración en las raíces de los dientes involucrados en el traumatismo.

Dos años después de la avulsión, tanto la radiografía intraoral como el aspecto externo (figs. 17 y 18) son de normalidad y en el último control efectuado a los treinta y dos meses del traumatismo, el éxito del reimplante del diente avulsionado se constata tanto por la ausencia de sintomatología clínica, el aspecto exter- no de la corona y de la encía y la integridad de las partes blandas, como por el aspecto de normalidad de la raíz, corona, espacio periodontal y hueso alveolar que muestran la radiografía intraoral y la fotografía (figs. 19 y 20).

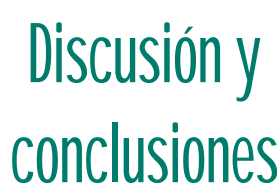

Existe un consenso generalizado en los estudios e investigaciones desarrollados por los diferentes autores para el mantenimiento a largo plazo en la boca del diente avulsionado que está íntimamente relacionado con los siguientes factores: el intervalo de tiempo extraoral -inferior a 60 minutos-, el medio de transporte húmedo siempre- y en leche principalmente -el intervalo extraoral superior a 15 minutos en seco, es causa de fracaso- ${ }^{18^{*}}$, el manejo del diente hasta su reinserción alveolar, evitando el daño radicular en su manipulación (no cepillarlo o sumergirlo en alcohol, agua oxigenada, hipoclorito, etc.), pues así se preserva la vitalidad de las células del ligamento periodontal ${ }^{1^{* *}}$ básica para la prevención de las reabsorciones, la ferulización ${ }^{9,{ }^{* 12}}$ con elementos no rígidos que permitan los movimientos fisiológicos, de corta duración (7 a 10 días) hasta estabilizar la movilidad del diente -si no hay fractura radicular- y el grado ${ }^{7}$ de desarrollo apical, pues un diente con el ápice abierto reimplantado precozmente tiene la posibilidad de revascularizar su pulpa ${ }^{19 *, 20}$

Hay que insistir en la divulgación informativa, como señala Alventosa ${ }^{12}$ y recoge el tríptico elaborado por $A E D E^{1{ }^{1 * *}}$, dirigidas a los niños y educadores en particular y a la población en general para mantener la calma y evitar las maniobras anteriormente descritas que puedan ensombrecer el pronóstico de estos casos.

La obturación tridimensional del conducto radicular con hidróxido de calcio en la primera fase del tratamiento y posteriormente con gutapercha y sellador en la segunda utilizados como se ha descrito y, la restauración estética del diente, finalizan el aspecto endodóntico del problema, pero no debemos descuidar el seguimiento a largo plazo por la posibilidad de complicaciones en éste $u$ otros dientes.

\section{Bibliografía recomendada}

Para profundizar en la lectura de este tema, el/los autor/es considera/an interesantes los artículos que aparecen señalados del siguiente modo: *de interés **de especial interés.

$1^{* *}$. Andreasen JO, Borum MK, Jacobsen HL, Andreasen FM. Replantation of $\mathbf{4 0 0}$ avulsed permanent incisors. 4. Factors related to periodontal ligament healing. Endod Dent Traumatol 1995;11(2):76-89.

El artículo destaca en el mantenimiento de las células del ligamento periodontal es fundamental para prevenir la reabsorción por reemplazo.

$2^{* *}$. Andresen JO, Andreasen FM. Avulsión denta-

ria. En: Andreasen JO. Lesiones dentarias traumáticas. Panamericana, 1990:113-31.

Libro de consulta y referente indispensable en la clínica dental como ayuda en el diagnóstico y posibilidades terapeúticas en los traumatismos dentales.

3. Donaldson M, Kinirons MJ. Factors affecting the time of onset of resorption in avulsed and replanted incisor teeth in children. Dent Traumatol 2001;17(5):205-9

4. Hiltz J, Trope M. Vitality of human lip fibroblasts in milk, Hanks balanced salt solution and Viaspan storage media. Endod Dent Traumatol 1991;7(2):69-72.

5. Barrett EJ, Kenny DJ. Survival of avulsed per- manent maxillary incisors in children following delayed replantation. Endod Dent Traumatol 1997;13(6):269-75

6*. Andreasen JO, Borum MK, Jacobsen HL, Andreasen FM. Replantation of $\mathbf{4 0 0}$ avulsed permanent incisors. 2. Factors related to pulpal healing. Endod Dent Traumatol 1995; 11(2):59-68.

Este artículo destaca que el mantenimiento de la vitalidad pulpar depende de la amplitud de la abertura del ápice, del tiempo extraoral y de su mantenimiento en medio húmedo.

RCOE, 2003, Vol 8, №4, 429-437 
7*. Andreasen JO, Borum MK, Jacobsen HL, Andreasen FM. Replantation of 400 avulsed permanent incisors. 3. Factors related to root growth. Endod Dent Traumatol 1995;11(2):6975 .

La relevancia de este artículo estriba en la ausencia de daño en la vaina de Hertwig para la continuidad del crecimiento radicular.

8. AAE. Directrices recomendadas para el tratamiento del diente permanente avulsionado. Publicadas en Endodoncia 1996;14(3): $138-40$

9*. von Arx T, Filippi A, Buser D. Splinting of traumatized teeth with a new device: TTS (Titanium Trauma Splint). Dent Traumatol 2001;17(4):180-4.

Se insiste en la importancia de una férula no rígida que permita los movimientos fisiológicos del diente.

10*. Andreasen JO, Borum MK, Jacobsen HL, Andreasen FM. Replantation of 400 avulsed permanent incisors. 1. Diagnosis of healing complications. Endod Dent Traumatol 1995; 11(2):51-8.

La pérdida de dientes en el período $1965-88$, fue ligeramente superior en aquellos dientes que presentaban un desarrollo radicular incompleto.

11**. AEDE. «Cuando tu diente salta de la

boca...» Tríptico informativo, revisado y editado en 2002.

Publicación divulgativa que mediante dibujos y textos explicativos de fácil comprensión, indica con claridad las maniobras de actuación en estos casos.

12. Paveck DI, Radtke PK. Postreplantation management of avulsed teeth: an endodontic literature review. Gen Dent 2000;48(2):176-81

13. Cvek M. Treatment of non-vital permanent incisors with calcium hydroxide. I Follow-up of periapical repair and apical closure of inmature roots. Odontol Revy 1972;23:27-34

14. Alventosa, JA. Avulsión dentaria: A propósito de dos casos. Endodoncia 1996;14(3):128-35

15. Berástegui, E: En Canalda C, Brau E. Endo- doncia: Técnicas clínicas y bases científicas. Barcelona, Masson 2001

16. Caliskan MK, Turkum M, Gokay N. Delayed replantation of avulsed mature teeth with calcium hydroxide treatment. J Endod 2000; 26(8):472-6.

17. Kinoshita S, Kojima R, Taguchi Y, Noda T. Tooth replantation after traumatic avulsion: a report of ten cases. Dent Traumatol 2002; 18(3):153-6.

18. Boyd DH, Kinirons MJ, Gregg TA. A prospective study of factors affecting survival of replanted permanent incisors in children. Int J Paediatr Dent 2000;10(3):200-5.

19*. Trope M. Avulsion and replantation. Refuat Hapeh Vehashinayim 2002;19(2):6-15

Es una revisión actualizada de los conocimientos sobre avulsión y reimplante, además del manejo del diente dentro y fuera del ámbito de la clínica dental. Detalla el protocolo a seguir considerando el grado de desarrollo radicular y el tiempo extraoral. 
RCOE, 2003, Vol 8, №4, 429-437 